\title{
EXPLORATION OF POTENTIALLY BIOACTIVE PEPTIDES GENERATED FROM THE ENZYMATIC HYDROLYSIS OF HEMPSEED PROTEINS
}

Gilda Aiello, Carmen Lammi, Giovanna Boschin, Chiara Zanoni, Anna Arnoldi*

Department of Pharmaceutical Sciences, University of Milan, 20133 Milan, Italy

\section{ABSTRACT}

The seed of industrial hemp is an underexploited protein source. In view of a possible use in functional foods, a hempseed protein concentrate was hydrolyzed with pepsin, trypsin, pancreatin, or a mixture of these enzymes. A detailed peptidomic analysis using data-dependent acquisition showed that the numbers of peptides identified ranged from 90 belonging to 33 parent proteins in the peptic hydrolysate to 9 belonging to 6 proteins in the pancreatin digest. The peptic and tryptic hydrolysates resulted to be the most efficient inhibitors of 3hydroxymethyl-coenzyme A reductase activity, when tested on the catalytic domain of the enzyme. Using the open access tools PeptideRanker and BIOPEP, a list of potentially bioactive peptides was generated: the alleged activities included the antioxidant property, the glucose uptake stimulating activity, the inhibition of dipeptidyl peptidase-IV (DPP-IV) and of angiotensin converting enzyme I (ACE).

Keywords: bioactive peptides, Cannabis sativa, LC-MS/MS, hempseed hydrolysates, HMGCoAR, peptidomics

\section{INTRODUCTION}

Currently, there is a growing interest for the production of food protein hydrolysates containing bioactive peptides for potential applications in functional foods. So far, much research has been focused on the use of animal proteins (milk, egg, fish, meat) as raw materials for the production of such bioactive peptides. ${ }^{1}$ However, edible plants and mainly their seeds represent cheap and environmentally sustainable protein sources currently investigated for the same purpose. ${ }^{2}$

Certainly, a complete information on peptide sequences is crucially relevant in order to elucidate the correlation between the composition of such hydrolysates and the observed biological activities and to elucidate the molecular mechanisms involved. This knowledge is, therefore, a key factor in the development of applications in nutraceuticals and functional foods. In fact, the specific 
bioactivity of food peptides against various molecular targets depends on their structural properties, such as amino acid composition, length and physicochemical characteristics of the amino acid side chains, as well as their bulkiness, hydrophobicity, and charge. ${ }^{3}$ Given a single starting material, different peptide profiles may be achieved under varying hydrolytic conditions, since enzymatic activity is a function of structural characteristics of the substrate on which the proteases act. ${ }^{4}$ To date, the characterization of the relative similarities and differences between such peptide profiles remains largely unstudied. In this context, the advent of peptidomics based on advanced analytical techniques, in particular mass spectrometry, allows to elucidate the full components present in a specific peptide mixture. Indeed, continued advances in tandem MS technologies provide today more and more accurate identifications and quantifications of such peptides. $^{5}$ Accordingly, this technology has attracted the attention of food scientists and nutritionists as a promising approach for the characterization of food protein hydrolysates. ${ }^{6-8}$

While proteomics usually comprises molecular weights from approx. 700 to $3000 \mathrm{Da}$ with a dynamic range of twelve orders of magnitude, peptidomics certainly spans over a greater peptide length distribution showing instead a similar dynamic range. ${ }^{8}$ Moreover, the high concentration of low molecular weight peptides in food hydrolysates is undoubtedly an analytical challenge to peptidomic analysis, and research in this area is yielding significant results especially for the identification of small peptides.

The seed of industrial hemp, i.e. the non-drug cultivars of Cannabis sativa, is certainly an underexploited protein-rich seed. ${ }^{9}$ Hempseed proteins are an excellent natural source of highly digestible amino acids when compared to other protein sources, such as borage meal, canola meal, and heated canola meal. ${ }^{10,11}$ Interestingly, recent investigations have demonstrated that peptides produced by enzymatic hydrolysis of hempseed proteins provide several biological activities, including the antihypertensive one ${ }^{12,13}$ and antioxidant one. ${ }^{12,14,15}$

In addition, a few literature evidences indicate that the inclusion of hempseed protein in the diet of suitable animal models modulates their lipid profile in a favorable way. ${ }^{16-18}$ Since proteins are hydrolyzed during digestion, the activity may be due to specific peptides encrypted in the protein sequences that are released by digestion and absorbed at intestinal level. This has stimulated our interest for assessing whether the enzyme selection and technical conditions may modulate the hypocholesterolemic properties of hempseed peptides. ${ }^{19}$ In fact, the bioactivity of food protein hydrolysates depends strictly on these parameters. ${ }^{20}$

Based on these considerations, the overall objective of the present study was to compare the efficiency of some enzymes and/or enzyme combinations in the production of bioactive protein hydrolysates from hempseed. In details, the specific objectives were: (i) the optimization of the 
release of the peptides from hempseed protein using different enzymes; (ii) the identification and characterization of each hydrolysate by a shotgun MS based approach; iii) the evaluation of the inhibitory activity of each hydrolysate on 3-hydroxy-3-methyl-glutaryl-coenzyme A reductase (HMGCoAR), a key enzyme in cholesterol metabolism; and (iv) the prediction of additional biological activities using in silico bioinformatics tools.

\section{MATERIALS AND METHODS}

Reagents. All chemicals and reagents were of analytical grade. LC-grade $\mathrm{H}_{2} \mathrm{O}(18 \mathrm{M} \Omega \mathrm{cm})$ was prepared with a Milli-Q $\mathrm{H}_{2} \mathrm{O}$ purification system (Millipore, Bedford, MA, USA). Acetonitrile $(\mathrm{ACN})$, tris(hydroxymethyl)aminomethane (Tris- $\mathrm{HCl})$, hydrochloric acid $(\mathrm{HCl})$, ammonium bicarbonate, and HMGCoAR assay Kit were provided by Sigma-Aldrich (St. Louis, MO, USA). Pepsin from porcine gastric mucosa (P7012, lyophilized powder, $\geq 2,500$ units/mg protein), trypsin from bovine pancreas (T1426, lyophilized powder, $\geq 10,000$ units/mg protein), and pancreatin from porcin pancreas (P1625, powder, $3 \mathrm{x} \geq$ USP specification) were from Sigma-Aldrich (St. Louis, MO, USA). Bovine serum albumin (BSA) and $\beta$-mercaptoethanol were from Thermo Fisher Scientific (Life Techonoly, Milan Italy). Mini-Protean apparatus, precision plus protein standards, Bradford reagent and Coomassie Blue G-250 were purchased from Bio-Rad (Hercules, CA, USA).

Protein concentrate preparation. The seeds of the species $C$. sativa (cultivar Futura) were provided by the Institute of Agricultural Biology and Biotechnology, CNR (Milan, Italy). The hempseed protein concentrate (HPC) was prepared applying the method described previously with some modifications. ${ }^{21}$ Briefly, $2 \mathrm{~g}$ of defatted hempseed flour were homogenized with $15 \mathrm{~mL}$ of $100 \mathrm{mM}$ Tris- $\mathrm{HCl} / 0.5 \mathrm{M} \mathrm{NaCl}$ buffer, $\mathrm{pH}$ 8.0. The extraction was performed in batch at $4{ }^{\circ} \mathrm{C}$ overnight. The solid residue was eliminated by centrifugation at $5,800 \mathrm{~g}$ for $30 \mathrm{~min}$ at $4{ }^{\circ} \mathrm{C}$ and the supernatant was dialyzed against $100 \mathrm{mM}$ Tris-HCl buffer, $\mathrm{pH} 8.0$ for $36 \mathrm{~h}$ at $4{ }^{\circ} \mathrm{C}$. The protein content of HPC, assessed according to the Bradford method using BSA as standard, was 15.4 $\mathrm{mg} / \mathrm{mL}$.

Preparation of the hempseed protein hydrolysates. The HPC, dissolved in $100 \mathrm{mM}$ Tris$\mathrm{HCl} / 0.5 \mathrm{M} \mathrm{NaCl}$ buffer $\mathrm{pH}$ 8.0, was hydrolyzed using three single enzymes: i.e. pepsin, trypsin, pancreatin or, in order to mimic the gastrointestinal digestion, a combination of the same enzymes. The peptic hydrolysis was performed adjusting the $\mathrm{pH}$ to 2 by adding $1 \mathrm{M} \mathrm{HCl}$ to the HPC. The enzyme solution ( $4 \mathrm{mg} / \mathrm{mL}$ in $\mathrm{NaCl} 30 \mathrm{mM}$ ) was added in a 1:50 enzyme/hempseed protein ratio (w/w). The mixture was incubated for $16 \mathrm{~h}$ and the enzyme inactivated changing the $\mathrm{pH}$ to 7 by 
adding $1 \mathrm{M} \mathrm{NaOH}$. Tryptic and pancreatic hydrolysis was performed directly in the buffer solution adding trypsin $(4 \mathrm{mg} / \mathrm{mL}$ in $\mathrm{HCl} 1 \mathrm{mM})$ and pancreatin $\left(4 \mathrm{mg} / \mathrm{mL}\right.$ in $\left.\mathrm{H}_{2} \mathrm{O}\right)$ in a $1: 50$ enzyme/HPC ratio $(\mathrm{w} / \mathrm{w})$. After $16 \mathrm{~h}$ incubation, the digestion was stopped changing the $\mathrm{pH}$ to 3 by adding $1 \mathrm{M}$ $\mathrm{HCl}$. The simulated gastrointestinal digestion was initiated by the addition of pepsin [1:20 (w/w) enzyme/hempseed protein ratio] stirring the mixture for $2 \mathrm{~h}$ at $\mathrm{pH} 2$. After that, the reaction mixture was adjusted to $\mathrm{pH} 8.5$ with $1 \mathrm{M} \mathrm{NaOH}$ followed by the addition of a mixture of trypsin and pancreatin, each at a 1:25 enzyme/HPC (w/w) ratio. The mixture was incubated at $37{ }^{\circ} \mathrm{C}$ for $4 \mathrm{~h}$. The enzymatic reaction was terminated by adjusting the mixture to $\mathrm{pH} 3$ with $1 \mathrm{M} \mathrm{HCl}$. Each digestion was stopped by holding at $95^{\circ} \mathrm{C}$ for $10 \mathrm{~min}$ to ensure a complete inactivation of residual enzyme activity.

All digestion processes were performed at $37{ }^{\circ} \mathrm{C}$ and all obtained hydrolysates were purified separating the undigested proteins, the high molecular-weight polypeptides and the intact enzymes by ultrafiltration through membranes with a 3-kDa molecular weight cut-off (MWCO) (Millipore, USA) at $12,000 \mathrm{~g}$ for $30 \mathrm{~min}$ at $4{ }^{\circ} \mathrm{C}$. Finally, the permeated peptides were collected and stored at $-20{ }^{\circ} \mathrm{C}$ until used in further experiments.

Evaluation of the percent peptide yield and DH of the hydrolysates. The peptide concentration $(\mu \mathrm{g} / \mu \mathrm{L})$ of each hydrolysate was determined according to a literature method, ${ }^{22}$ which is based on chelating the peptide bonds by $\mathrm{Cu}(\mathrm{II})$ in alkaline media and monitoring the change of absorbance at $330 \mathrm{~nm}$ according to Lammi et al., 2016. ${ }^{23}$ The percent peptide yield from the HPC was determined as the ratio between peptide concentration and the protein concentration of the nonhydrolyzed HPC, estimated by Bradford assay. The degree of hydrolysis was determined by the OPA assay, according to Nielsen et al., $2001^{24}$ with some modifications. This assay is based on the formation of an adduct between the $\alpha$-amino groups of peptides and the OPA reagent. The assay consisted of mixing $200 \mu \mathrm{L}$ of OPA reagent with $26.6 \mu \mathrm{L}$ of hydrolysates. After $1.5 \mathrm{~min}$ of incubation at $25^{\circ} \mathrm{C}$, the absorbance was measured at $340 \mathrm{~nm}$ using the Synergy $\mathrm{H} 1$ fluorescent plate reader (Biotek, Bad Friedrichshall, Germany).

Tricine SDS-PAGE Separation. To monitor the efficacy of hydrolysis, Tris-Tricine SDS-PAGE was used following a literature method. ${ }^{25}$ A $16.0 \%$ resolving gel using $40 \%$ acrylamide/bis solution (19:1) and $6 \mathrm{M}$ urea was prepared and overlaid with 5\% stacking gel. A fixed volume $(500 \mu \mathrm{L})$ of each hydrolysate was dried and dissolved in $15 \mu \mathrm{L}$ of $2 \mathrm{X}$ loading buffer containing SDS, $\beta$-mercaptoethanol, glycerol and Coomassie G-250 stain. The mixture was heated in a boiling 
water bath for $5 \mathrm{~min}$, vortexed for $30 \mathrm{sec}$, and allowed to cool to room temperature. All the $15 \mu \mathrm{L}$ of the sample were loaded onto the gel. A mixture of proteins (range $26.7 \mathrm{kDa}-1.4 \mathrm{kDa}$, Biorad) was used as a broad range MW marker. The cathodic compartment were filled with Tris-Tricine buffer, $\mathrm{pH} 8.3$, containing $0.1 \%, \mathrm{~m} / \mathrm{v}$ SDS, whereas the anodic compartment was filled with Tris$\mathrm{HCl}, \mathrm{pH}$ 8.9. Electrophoreses were run on a Mini-Protean II Cell at $100 \mathrm{~V}$ until the dye front reached the gel bottom. The resolved protein bands were stained by immersing the gel in a solution containing 45\% methanol, $10 \%$ glacial acetic acid, and 0.25\% Coomassie Brilliant Blue R-250 for $1.5 \mathrm{~h}$. To visualize the bands, the gel was destained in a solution containing $45 \%$ methanol and $10 \%$ glacial acetic acid until they were clearly visible.

MS/MS peptide profiling. The peptide solutions $(100 \mu \mathrm{L})$ were desalted on SepPak C18 cartridge (Thermo Fisher Scientific, Life Technology, Milan Italy) conditioned with $\mathrm{MeOH}$ and rinsed with $0.1 \%$ FA. Peptides were eluted from the SPE column with $280 \mu \mathrm{L}$ ACN: $\mathrm{H}_{2} \mathrm{O}(80: 20$, v/v) containing 0.1\% FA and then dried in a Speed-Vac (Martin Christ). Each sample was reconstituted with $20 \mu \mathrm{L}$ of a solution of $2 \%$ ACN, $0.1 \%$ FA, properly diluted, and analyzed on a SL IT mass spectrometer interfaced with a HPLC-Chip Cube source (Agilent Technologies, Palo Alto, CA, USA). Each sample was loaded onto a $40 \mathrm{~nL}$ enrichment column (Zorbax 300SB-C18, $5 \mu \mathrm{m}$ pore size), and separated onto a $43 \mathrm{~mm} \times 75 \mu \mathrm{m}$ analytical column packed (Zorbax 300SB-C18, $5 \mu \mathrm{m}$ pore size). Separation was carried out in gradient mode at a flowrate of $300 \mathrm{~nL} / \mathrm{min}$. The LC solvent A was $95 \%$ water, $5 \% \mathrm{ACN}, 0.1 \%$ formic acid; solvent $\mathrm{B}$ was $5 \%$ water, $95 \% \mathrm{ACN}, 0.1 \%$ formic acid. The nano pump gradient program was as follows: $5 \%$ solvent $\mathrm{B}(0 \mathrm{~min}), 80 \%$ solvent B (0-40 min), 95\% solvent B (40-45 min), and back to 5\% in $5 \mathrm{~min}$. A reconditioning at the initial chromatographic conditions was conducted for 5 minutes. The drying gas temperature was 300 ${ }^{\circ} \mathrm{C}$, flow rate $3 \mathrm{~L} / \mathrm{min}$ (nitrogen). Data acquisition occurred in positive ionization mode. Capillary voltage was $-1950 \mathrm{~V}$, with endplate offset $-500 \mathrm{~V}$. Full scan mass spectra were acquired in the mass range from $m / z, 300$ to 2000 Da. LC-MS/MS analysis was performed in data-dependent acquisition AutoMS(n) mode. In order to increase the number of identified peptides, three technical replicates (LC-MS/MS runs) were run for each of the three experimental replicates.

Database searching, protein identification and validation. The MS/MS data were analyzed by Spectrum Mill Proteomics Workbench (Rev B.04.00, Agilent), consulting the C. sativa (531 sequences) protein sequences database downloaded from the National Center for Biotechnology Information (NCBI). The enzymes selected were pepsin and trypsin for the analysis of the peptic and tryptic hydrolysates, respectively; whereas none specific cleavage was selected for analyzing 
the pancreatic and co-digested hydrolysates. Two missed cleavages were allowed to each enzyme used; peptide mass tolerance was set to 1.2 Da and fragment mass tolerance to 0.9 Da. For quality assignment, a sequence tag lengths $>4$ was used. Threshold used for peptide identification score $\geq 6$; Scored Peak Intensity SPI $\% \geq 70 \%$; autovalidation strategy both in peptide mode and in protein polishing mode was performed using FDR cut-off $\leq 1.2 \%$. Protein abundance was performed at protein level using Total Protein Spectral Intensity (TPSI) based on the summation of peptide intensities, calculated from extracted ion chromatograms from each precursor ions.

Amino acid composition. The amino acid compositions of the hempseed hydrolysates and the isoelectric points (pI) were determined using ProtParam tool (http://web.expasy.org/protparam/). ${ }^{26}$ Hierarchical clustering analysis (HCA) and its visualization were performed using Cluster 3.0 and Java TreeView, respectively. HCA allows the presentation of cluster results in a dendrogram, where the similarity among the samples is determined from the value on the distance axis at which they join in a single cluster (the smaller the distance, the more similar the sample). Euclidean distance was used to calculate the matrix of all samples. The complete linkage method was then used in the assignment of clusters.

HMGCoAR activity assay. The HMGCoAR inhibitory activity of each hydrolysate was evaluated using a commercial assay Kit providing HMGCoAR (catalytic domain), NADPH, assay buffer, and substrate solution. The experiments were carried out at $37{ }^{\circ} \mathrm{C}$ following the manufacturer's instructions. Each reaction $(200 \mu \mathrm{L})$ was prepared by adding the reagents in the following order: $1 \mathrm{X}$ assay buffer; $0.2,0.3,0.5$, and $1.0 \mathrm{mg} / \mathrm{mL}$ of co-digested peptides, with 1.0 , and $2.0 \mathrm{mg} / \mathrm{mL}$ of the peptides digested with pancreatin, $0.1,0.25,0.35,0.5$, and $1.0 \mathrm{mg} / \mathrm{mL}$ of the peptides digested with pepsin, or $0.2,0.5$, and $1.0 \mathrm{mg} / \mathrm{mL}$ of the peptides digested with trypsin or vehicle $(\mathrm{C})$; NADPH $(4 \mu \mathrm{L})$; substrate solution $(12 \mu \mathrm{L})$; and finally HMGCoAR $(2 \mu \mathrm{L})$. Subsequently, the samples were mixed, and the absorbance at $340 \mathrm{~nm}$ was read by a microplate reader (Synergy H1 from Biotek, Bad Friedrichshall, Germany) at 0 and 10 min. The HMGCoAdependent oxidation of NADPH and the inhibition properties of hempseed peptides were measured by the absorbance reduction, which is directly proportional to the enzyme activity.

Profile of potential biological activities and peptide ranking. The potential bioactivities of hempseed peptides were predicted using the open access tool PeptideRanker (http://bioware.ucd.ie/compass/biowareweb/), ${ }^{27}$ a web-based tool used to predict the probability of biological activity of peptide sequences. Using N-to-1 neural network probability, 
PeptideRanker provides peptide scores in the range of $0-1$. The maximum scores indicate the most active peptides, whereas the minimum scores denote the least active peptides. Here, only those peptides with a score higher than 0.6 were considered as potentially "bioactive". Subsequently, the lists of best-ranked peptides were submitted to the web-available database BIOPEP (http://www.uwm.edu.pl/biochemia/index.php/pl/biopep/).

Statistical analysis in the HMGCoAR activity assay. Statistical analyses were carried out by One-way ANOVA (Graphpad Prism 6) followed by Dunnett's test. Values were expressed as means $\pm \mathrm{SD}$; P-values $<0.05$ were considered to be significant.

\section{RESULTS}

Hydrolysis trend, yield, and DH of hempseed hydrolysates. In order to produce protein hydrolysates endowed with potential biological activities, HPC was digested using one enzyme, i.e. pepsin, trypsin, or pancreatin, or a mixture of the same enzymes in order to mimic the gastrointestinal digestion. The highest peptide yield was observed for the pancreatic hydrolysate (43\%), followed by the tryptic hydrolysate $(24.6 \%)$, the co-digested hydrolysate $(18.2 \%)$ and the peptic one (16\%). The DH values were $19.7 \%$ for peptic hydrolysate, $46.6 \%$ for tryptic, $47.5 \%$ for pancreatic, and $34 \%$ for codigested. These results indicate a direct correlation between the peptide yields and the $\mathrm{DH}$ values, the trends across all hydrolysates are comparable.

In order to monitor the efficiency of the hydrolysis, a tricine-SDS-PAGE was used to resolve the peptide pool composition of each hydrolysates. Figure 1 shows the profile of the molecular weight distribution at the end of digestion. The peptic hydrolysate showed many continuous, intense and unresolved bands in the range from 3.5 to $26.6 \mathrm{kDa}$, the co-digested hydrolysate displayed another band-rich profile, whereas the tryptic and pancreatic presented only small bands between 6.5 and $26.6 \mathrm{kDa}$. The absence of intense bands indicated that these hydrolysates contained mostly very short peptides (MW smaller than $3.5 \mathrm{kDa}$ ) that had diffused through the gel. The results of the percent peptide yields and DH were in agreement with these findings: in fact, consistently, yields and DH were larger when the bands were more difficult to visualize on the gels.

Chemical characterization of the protein hydrolysates. The characterization of the four hydrolysates was carried out by HPLC-Chip MS/MS analysis. The results are summarized in Table 1S (Supplementary materials), which reports the identified peptides according to their parent proteins. The peptic hydrolysate was the richest both in terms of identified peptides and 
proteins. In fact, it was possible to detect 90 peptides belonging to 33 C. sativa proteins, whereas in the codigested sample 62 peptides belonging to 25 proteins were identified. In the tryptic digest, it was possible to detect 25 peptides accounting for 6 proteins, while only 9 peptides deriving from 6 proteins were identified in the pancreatic hydrolysate. Therefore, the composition in terms of proteins and peptides is very specific for each hydrolysate. Figure 2A shows the percent distribution of the peptides deriving from specific parent proteins in each hydrolysate. The peptic hydrolysate contained peptides derived from numerous proteins, with a small prevalence of the two isoforms of Edestin (6\% from Edestin 1 and 6\% from Edestin 2), as well as DNA-directed RNA polymerase subunit beta $(6 \%)$ and Protein Ycf2 $(6 \%)$. The percentage of peptides deriving from Edestin increased greatly in the tryptic hydrolysate (40\% from Edestin 1 and 24\% from Edestin 2). Phenylalanine ammonia-lyase and Ribulose 1,5-bisphosphate carboxylase/oxygenase were instead the most abundant parent proteins in the pancreatic hydrolysate, accounting for $34 \%$ and 22\%, respectively. On the contrary, Photosystem I P700 chlorophyll (10\%), Edestin 2 (8\%), NADH-ubiquinone oxidoreductase (6\%), and 4-coumarate:CoA ligase $(6 \%)$ were the parent proteins of most peptides in the co-digested hydrolysate. The Venn diagram (Figure 2B) highlights the distribution of the parent proteins among the hydrolysates. Only 13 proteins are common to the peptic and the co-digested hydrolysates, whereas none protein is shared by all hydrolysates. These results suggest a very high selectivity of the hydrolytic processes that produced peptide mixtures with different compositions.

Based on MS/MS results, the clustering of the molecular weights (MW) distribution of the peptides released after HPC digestion is reported in Figure 3A. Pepsin hydrolysis produced a high number of peptides that fall into the ranges of 1000-1500 and 2000-2500 Da, whereas the simulated gastrointestinal digestion yielded predominantly peptides in the 1500-2000 Da range. Hierarchical clustering analysis (HCA) was applied to classify all samples according to their amino acid composition (AAC) as reported in Figure 3B. The tryptic, peptic, and co-digested hydrolysates showed a similar AAC, whereas the pancreatic mixture displayed a different AAC. The amino acid similarity among all hydrolysates is the driven factory on which the clusters are built. Each step in the clustering process is illustrated by a joint of the tree. Glu, Gly, Pro, Phe, Val, and Try are frequently occurring in the peptic, tryptic, and co-digested hydrolysates, whereas they are poorly expressed in the pancreatic mixture. On the contrary, Met, Arg, Ala, and Cys were the most abundant amino acid residues in the pancreatic mixture.

Inhibitory effects of the hydrolysates on the HMGCoAR activity. In order to evaluate experimentally the ability of the different hydrolysates to inhibit the activity of HMGCoAR, ${ }^{23}$ 
an in vitro assay was performed using the purified catalytic domain of this enzyme. Peptide concentrations ranging from 0.2 to $2.0 \mathrm{mg} / \mathrm{mL}$ were tested. Figure 4 shows that, after incubation with the peptic hydrolysate $(0.25,0.5$, and $1.0 \mathrm{mg} / \mathrm{mL})$, the HMGCoAR activity was inhibited by $24.5 \pm 1.7 \%$ ( $p<0.001), 61.1 \pm 0.7 \%(p<0.001)$, and $80.0 \pm 4.0 \%(p<0.001)$, respectively, versus the control. After the incubation with the tryptic hydrolysate $(0.2,0.5$, and $1 \mathrm{mg} / \mathrm{mL})$, the HMGCoAR activity was inhibited by $24.6 \pm 4.6 \%(\mathrm{p}<0.05), 58.4 \pm 1.1 \%$ ( $\mathrm{p}<0.001), 93.3 \pm 9.3 \%$ ( $\mathrm{p}<0.001)$, respectively, versus the control. After incubation with the co-digested hydrolysate $(0.2,0.5$, and $1.0 \mathrm{mg} / \mathrm{mL})$, the HMGCoAR activity was inhibited by $16.2 \pm 12.6 \%(\mathrm{p}<0.01), 50.6 \pm 2.3 \%(\mathrm{p}<0.001), 47.4 \pm 1.5 \%(\mathrm{p}<0.001)$. Finally, after incubation with the pancreatic hydrolysate the HMGCoAR activity was not significantly inhibited at 1.0 $\mathrm{mg} / \mathrm{mL}$, whereas a moderate but significant inhibition by $11.7 \pm 6.4 \%(\mathrm{p}<0.05)$ was observed at $2.0 \mathrm{mg} / \mathrm{mL}$.

Peptide ranking, protein abundance and bioactivity searching. In order to extend the investigation to other potential bioactivities, the peptidome maps were ranked by the tool PeptideRanker. At the end of this process, only those peptides showing score values higher than 0.6 were considered as potentially bioactive. The data reported in Table $\mathbf{1}$ demonstrate that there is not any correlation between high-scored peptides and the total protein spectral intensity (TPSI) of the proteins from which they are released. In particular, as shown in Figure 5, a great number of potentially bioactive peptides belong to less abundant proteins. For example, QIQFEGFCRF (score 0.92) derives from DNA-directed RNA polymerase subunit beta, which is one of the least abundant proteins detected in the hydrolysates. On the contrary, only one peptide derived from Edestin 2, DIFNPRGG (score 0.74), was supposed to be bioactive.

In order to hypothesize their possible bioactivities, the best scored peptides were submitted to BIOPEP search (Table 1). The alleged biological activities included the inhibition of dipeptidyl peptidase-IV (DPP-IV) and of angiotensin converting enzyme I (ACE), the antioxidant property, and the glucose uptake stimulating activity. Most bioactive peptides were detected in the hydrolysates deriving from the peptic and/or the simulated gastrointestinal digestion. Following the bioinformatic prediction, bioactivities are prevalently provided by short sequences of two or three amino acids included in their structures.

\section{DISCUSSION}

The first objective of the study was the characterization of the composition of the four hydrolysates, an important step in the pathway to evaluate their potential use as functional 
ingredients. Having this final goal, all enzymatic digestions were performed avoiding the use of reducing and alkylating agents in order to produce, as far as possible, unmodified and natural peptides. This choice of course partially impaired the hydrolytic efficiency of the enzymes.

All employed enzymes were endopeptidases that, with the exception of trypsin, randomly hydrolyze peptide bonds within the protein sequences, producing peptides differing in amino acid sequences and sizes. The resulting hydrolysates were diverse in terms of composition and percent yield of peptides. Pancreatin gave the highest percent yield: this may be attributed to the endo- and exo-peptidase activities of this enzyme, which increases protein digestion through hydrolysis of more peptide bonds, when compared to enzymes only endowed with an endopeptidase activity. ${ }^{28}$ Another high percent yield was observed with trypsin, even if this enzyme is well known for the high selectivity and specificity in site cutting recognition. A higher peptide yield is the expected outcome for increased protein breakdown and a marker of the hydrolytic process efficacy. The consequence of the high hydrolytic efficiency of these enzymes was the relatively small number of peptides that were identified in their hydrolysates, probably due to an extensive production of very short peptides, i.e. di-, tri- and tetra peptides, which are difficult to detect using a datadependent shotgun approach.

The identified peptides ranged from 7 to 29 amino acid residues, i.e. between $747 \mathrm{Da}$ and 3211 $\mathrm{Da}$, in agreement with the ultrafiltration separation that had been performed with a cut-off of 3 $\mathrm{kDa}$. These values correspond to peptides slightly longer than those reported in other studies after similar digestions of various animal proteins. ${ }^{29}$ Possibly, this might be explained by the protease inhibitors present in most plant seeds. In addition, the missing reduction and alkylation of the disulfide bonds reduced the proteolytic activity of each enzyme resulting in longer peptides. In order to investigate the different features of the hydrolysates, the HCA of the AAC of all identified peptides was employed combining the heat map with a dendrogram. The clustering provides the basis for guiding reasonable enzyme selection in order to produce hydrolysates endowed of specific chemicals features. As shown by Figure 3B, peptic and co-digested hydrolysates form two very close clusters according to their amino acid similarity. The AAC of the tryptic hydrolysate has also some similarity with the peptic and co-digested hydrolysates, but it falls at a wider distance. On the contrary, the pancreatic hydrolysate is well separated from the others. The peptic and codigested clusters are near, possibly the effects of pepsin prevails since this enzyme is the first applied in the codigestion. The tryptic cluster falls at a certain distance, since its cut sites are different from those recognized by pepsin. Finally, the pancreatic one is the most distant, since in this case the peptide hydrolysate is generated either by endo- or exopeptidase action. 
Apparently, their substantial structural diversities reflect also their different capability of inhibiting the activity of HMGCoAR, a key enzyme in the synthesis of endogenous cholesterol and the main target of statins, which interact with this enzyme as competitive inhibitors. ${ }^{30}$ The experiments performed using the purified catalytic domain of this enzyme showed that the tryptic and peptic hydrolysates were the best inhibitors (Figure 4), whereas the pancreatin hydrolysate was the least active, in line with the clustering provided by the HCA analysis. The pancreatic hydrolysate contains numerous residues of hydrophilic amino acids, such as Glu, Ser, Arg, and Lys, whereas it is completely devoid of Pro and Val, which are abundant in the other hydrolysates. This may be related to a synergistic effect of the hydrophobic peptides present in the mixtures, since the hypocholesterolemic effect is correlated to an increased hydrophobicity. ${ }^{31}$

In a previous paper, we have investigated the interaction of some soy peptides with the catalytic domain of HMGCoAR using in silico modeling studies. ${ }^{32}$ Medium size peptides, containing 8-10 amino acid residues and characterized by a hydrophobic N-terminus and a negatively charged Cterminus, appeared to be particularly favorable for interacting with HMGCoAR. The negatively charged C-terminal portion is primarily involved in the inhibition by mimicking most of the polar interactions that are clearly seen also in statins, ${ }^{32}$ whereas the hydrophobic $\mathrm{N}$-terminal portion is inserted in a deeper and rather polar sub-pocket that corresponds roughly to that harboring the NADPH cofactor. In fact, HMGCoAR contains a second relevant domain that is capable of accepting NADPH: a peptide that prevents this binding impairs the catalytic activity of the enzyme. ${ }^{32}$

In order to predict other potential activities, it was decided to use cost effective and time-saving computer simulated approaches, such as PeptideRanker and BIOPEP. It is important, however, to underline that these tools take into consideration only some possible biological activities, excluding for example the inhibition of HMGCoAR. At the end of the procedure, 22 peptides were postulated to be bioactive. In agreement with the features of BIOPEP, the main proposed activities were the inhibition of dipeptidyl peptidase-IV (DPP-IV) and of angiotensin converting enzyme I (ACE), the antioxidant properties, and the glucose uptake stimulating activity. The forecasted activities are linked to specific short sequences, mostly composed by two or three amino acid residues, encrypted in their sequences. Specifically, PWT, WPL, and VKV provide antioxidant activities, which could depend on the presence of substantial amounts of hydrophobic, branchedchain, or aromatic amino acid residues. The hydrophobicity is also important to enhance their permeability into the target organs through hydrophobic associations with the cell membrane lipid bilayer, promoting the achievement of potent antioxidant effects. ${ }^{33}$ In the meanwhile, the compresence of hydrophobic or aromatic amino acids at the C-terminus as well as of hydrophobic 
and negative ionizable functions (Thr, Glu, Asp, Ser, Met) positively contributes to an effective ACE inhibition. 1, 34, 35 Specifically, the sequences LSP, FEP, and IAE fall in this category. However, also branched-chain aliphatic amino acids at the C-terminus as well as hydrophobic amino acids at the N-terminus, such as IFL, LLP, AVL, LLF, contribute to high ACE-inhibitory activities. ${ }^{28,36}$ Finally, also the small sequence GP is expected to provide bioavailability and ACEinhibitory activity owing to its short sequence, hydrophobicity, and theoretical stability to pepsin and trypsin cleavage. ${ }^{37}$ The ACE inhibitory activity as well as the antioxidant activity of hempseed hydrolysates are confirmed experimentally by literature. ${ }^{28}$

Another proposed activity is the inhibition of DPP-IV. This enzyme is a new molecular target correlated with the development of type 2 diabetes. ${ }^{38}$ The peptides capable of inhibit the DPP-IV activity have in general a hydrophobic character and a length from 2 to 8 amino acids. Very often, they contain a Pro residue in their sequence located at the first, second or third or fourth N-terminal position, which is flanked by Leu, Val, Phe, Ala or Gly. ${ }^{39,40}$ A paper has investigated the DPP-IV inhibitory activity of hempseed protein hydrolysates obtained treating a HPC with different enzymes obtaining a first indication of a moderate activity also on this enzyme. ${ }^{41}$

In conclusion, it seems possible to affirm that there are good prospective that hempseed hydrolysates may be used as multipurpose ingredients in functional foods. Of course, when discussing the bioactivities of food peptides an open issue remains their bioavailability. In case of hempseed peptides, this problem is still to be taken into consideration. However, it is useful to remind that different authors have confirmed the bioavailability of peptides deriving from other food proteins. ${ }^{23,42-44}$

\section{AUTHOR INFORMATION}

\section{Corresponding Author}

Anna Arnoldi, Department of Pharmaceutical Sciences, University of Milan, via Mangiagalli 25, 20133 Milan, Italy. E-Mail: anna.arnoldi@unimi.it, tel.: +390250319372, fax: +390250319343 .

\section{Author contributions}

Experiment ideation and design: GA and CL. Experiments \& data analysis: protein hydrolysate preparation \& mass spectrometry: GA; inhibition of HMGCoAR activity: CL \& CZ. Manuscript writing: GA, CL \& AA, figure preparation CZ. 
409 ACKNOWLEDGMENTS

410 We are indebted to Carlo Sirtori Foundation (Milan, Italy) for having provided part of 411 equipment used in this experimentation.

412

413 ABBREVIATIONS USED

414 AAC, amino acid composition; ACE, angiotensin converting enzyme I; ACN, acetonitrile; 415 BSA, bovine serum albumin; DPP-IV, dipeptidyl peptidase-IV; HCA, hierarchical cluster 416 analysis; HMGCoAR, 3-hydroxy-3-methylglutaryl coenzyme A reductase; MW, molecular 417 weight; MWCO, molecular weight cut-off; PMSF, phenylmethanesulfonyl fluoride; SDS418 PAGE, sodium dodecyl sulphate - polyacrylamide. HPC, protein concentrate; TPSI, Total 419 Protein Spectral Intensity.

420

421 


\section{References}

1. Martínez-Maqueda, D.; Miralles, B.; Recio, I.; Hernández-Ledesma, B., Antihypertensive peptides from food proteins: a review. J. Food Funct. 2012, 3 (4), 350-61.

\section{Foltz, M.; Meynen, E. E.; Bianco, V.; van Platerink, C.; Koning, T. M.; Kloek, J.,} Angiotensin converting enzyme inhibitory peptides from a lactotripeptide-enriched milk beverage are absorbed intact into the circulation. J. Nutr. 2007, 137 (4), 953-8.

3. Pripp, A. H.; Isaksson, T.; Stepaniak, L.; Sorhaug, T.; Ardo, Y., Quantitative structure activity relationship modelling of peptides and proteins as a tool in food science. Trends Food Sci Technol. 2005, 16 (11), 484-494.

4. Holton, T. A.; Dillon, E. T.; Robinson, A.; Wynne, K.; Cagney, G.; Shields, D. C., Optimal computational comparison of mass spectrometric peptide profiles of alternative hydrolysates from the same starting material. Lwt-Food Sci Technol 2016, 73, 296-302.

5. Michalski, A.; Damoc, E.; Hauschild, J. P.; Lange, O.; Wieghaus, A.; Makarov, A.; Nagaraj, N.; Cox, J.; Mann, M.; Horning, S., Mass spectrometry-based proteomics using Q Exactive, a highperformance benchtop quadrupole Orbitrap mass spectrometer. Mol Cell Proteomics 2011, 10 (9), M111.011015.

6. Ibáñez, C.; Simó, C.; García-Cañas, V.; Cifuentes, A.; Castro-Puyana, M., Metabolomics, peptidomics and proteomics applications of capillary electrophoresis-mass spectrometry in Foodomics: a review. Anal Chim Acta 2013, 802, 1-13.

7. Lahrichi, S. L.; Affolter, M.; Zolezzi, I. S.; Panchaud, A., Food peptidomics: large scale analysis of small bioactive peptides--a pilot study. J. Proteomics 2013, 88, 83-91.

8. Panchaud, A.; Affolter, M.; Kussmann, M., Mass spectrometry for nutritional peptidomics: How to analyze food bioactives and their health effects. J. Proteomics 2012, 75 (12), 3546-59.

9. Aiello, G.; Fasoli, E.; Boschin, G.; Lammi, C.; Zanoni, C.; Citterio, A.; Arnoldi, A., Proteomic characterization of hempseed (Cannabis sativa L.). J. Proteomics 2016, 147, 187-196.

10. Malomo, S. A.; He, R.; Aluko, R. E., Structural and functional properties of hemp seed protein products. J. Food Sci 2014, 79 (8), C1512-21. 
450 11. Wang, X.-S.; Tang, C.-H.; Yang, X.-Q.; Gao, W.-R., Characterization, amino acid 451 composition and in vitro digestibility of hemp (Cannabis sativa L.) proteins. Food Chem. 2008, 107 452 (1), 11-18.

453 12. Girgih, A. T.; Alashi, A. M.; He, R.; Malomo, S. A.; Raj, P.; Netticadan, T.; Aluko, R. E., A 454 novel hemp seed meal protein hydrolysate reduces oxidative stress factors in spontaneously 455 hypertensive rats. Nutrients 2014, 6 (12), 5652-5666.

456 13. Girgih, A. T.; He, R.; Aluko, R. E., Kinetics and molecular docking studies of the inhibitions 457 of angiotensin converting enzyme and renin activities by hemp seed (Cannabis sativa L.) peptides. $J$ 458 Agric. Food Chem. 2014, 62 (18), 4135-4144.

459 14. Girgih, A. T.; Udenigwe, C. C.; Aluko, R. E., In vitro antioxidant properties of hemp seed 460 (Cannabis sativa L.) protein hydrolysate fractions. J. Am. Oil. Chem. Soc. 2011, 88 (3), 381-389.

461 15. Girgih, A. T.; Udenigwe, C. C.; Aluko, R. E., Reverse-phase HPLC separation of hemp seed 462 (Cannabis sativa L.) protein hydrolysate produced peptide fractions with enhanced antioxidant 463 capacity. Plant Foods Hum. Nutr. 2013, 68 (1), 39-46.

464 16. Gavel, N. T.; Edel, A. L.; Bassett, C. M. C.; Weber, A. M.; Merchant, M.; Rodriguez-Leyva, 465 D.; Pierce, G. N., The effect of dietary hempseed on atherogenesis and contractile function in aortae 466 from hypercholesterolemic rabbits. Acta Physiol. Hung. 2011, 98 (3), 273-283.

467 17. Prociuk, M. A.; Edel, A. L.; Gavel, N. T.; Lukas, A.; Pierce, G. N., Influence of dietary 468 hempseed on arrhythmia generation by ischemia/reperfusion. J. Mol. Cell Cardiol. 2004, 37 (1), 275469275.

470 18. Prociuk, M. A.; Edel, A. L.; Richard, M. N.; Gavel, N. T.; Ander, B. P.; Dupasquier, C. M. 471 C.; Pierce, G. N., Cholesterol-induced stimulation of platelet aggregation is prevented by a hempseed472 enriched diet. Can J Physiol Pharm 2008, 86 (4), 153-159.

473 19. Zanoni, C.; Aiello, G.; Arnoldi, A.; Lammi, C., Hempseed Peptides Exert

474 Hypocholesterolemic Effects with a Statin-Like Mechanism. J Agric Food Chem 2017, 475 10.1021/acs.jafc.7b02742

476 20. Ambigaipalan, P.; Al-Khalifa, A. S.; Shahidi, F., Antioxidant and angiotensin I converting 477 enzyme (ACE) inhibitory activities of date seed protein hydrolysates prepared using Alcalase,

478 Flavourzyme and Thermolysin. J Funct Foods 2015, 18, 1125-1137. 
479 21. Boschin, G.; Scigliuolo, G. M.; Resta, D.; Arnoldi, A., ACE-inhibitory activity of enzymatic 480 protein hydrolysates from lupin and other legumes. Food Chem 2014, 145, 34-40.

481 22. Levashov, P. A.; Sutherland, D. S.; Besenbacher, F.; Shipovskov, S., A robust method of 482 determination of high concentrations of peptides and proteins. Anal Biochem 2009, 395 (1), 111-2.

483

484

485

23. Lammi, C.; Aiello, G.; Vistoli, G.; Zanoni, C.; Arnoldi, A.; Sambuy, Y.; Ferruzza, S.; Ranaldi, G., A multidisciplinary investigation on the bioavailability and activity of peptides from lupin protein. J Funct Foods 2016, 24, 297-306.

24. Nielsen, P. M.; Petersen, D.; Dambmann, C., Improved method for determining food protein degree of hydrolysis. J Food Sci 2001, 66 (5), 642-646.

25. Schägger, H., Tricine-SDS-PAGE. Nat Protoc 2006, 1 (1), 16-22.

26. Wilkins, M. R.; Gasteiger, E.; Bairoch, A.; Sanchez, J. C.; Williams, K. L.; Appel, R. D.; Hochstrasser, D. F., Protein identification and analysis tools in the ExPASy server. Methods Mol Biol 1999, $112,531-52$.

27. Mooney, C.; Haslam, N. J.; Pollastri, G.; Shields, D. C., Towards the improved discovery and design of functional peptides: Common features of diverse classes permit generalized prediction of bioactivity. Plos One 2012, 7 (10).

28. Malomo, S. A.; Onuh, J. O.; Girgih, A. T.; Aluko, R. E., Structural and antihypertensive properties of enzymatic hemp seed protein hydrolysates. Nutrients 2015, 7 (9), 7616-32.

29. Bauchart, C.; Morzel, M.; Chambon, C.; Mirand, P. P.; Reynès, C.; Buffière, C.; Rémond, D., Peptides reproducibly released by in vivo digestion of beef meat and trout flesh in pigs. Br J Nutr 2007, 98 (6), 1187-95.

30. Sarver, R. W.; Bills, E.; Bolton, G.; Bratton, L. D.; Caspers, N. L.; Dunbar, J. B.; Harris, M. S.; Hutchings, R. H.; Kennedy, R. M.; Larsen, S. D.; Pavlovsky, A.; Pfefferkorn, J. A.; Bainbridge, G., Thermodynamic and structure guided design of statin based inhibitors of 3-hydroxy-3methylglutaryl coenzyme A reductase. J Med Chem 2008, 51 (13), 3804-13.

31. Zhong, F.; Zhang, X. M.; Ma, J. G.; Shoemaker, C. F., Fractionation and identification of a novel hypocholesterolemic peptide derived from soy protein Alcalase hydrolysates. Food Res Int 2007, 40 (6), 756-762. 
507 32. Lammi, C.; Zanoni, C.; Arnoldi, A.; Vistoli, G., Two Peptides from Soy $\beta$-Conglycinin 508 Induce a Hypocholesterolemic Effect in HepG2 Cells by a Statin-Like Mechanism: Comparative in 509 Vitro and in Silico Modeling Studies. J Agric Food Chem 2015, 63 (36), 7945-51.

510 33. Sarmadi, B. H.; Ismail, A., Antioxidative peptides from food proteins: a review. Peptides 511 2010, 31 (10), 1949-56.

512 34. Li, H.; Aluko, R. E., Identification and inhibitory properties of multifunctional peptides from 513 pea protein hydrolysate. J Agric Food Chem 2010, 58 (21), 11471-6.

514 35. Kobayashi, Y.; Yamauchi, T.; Katsuda, T.; Yamaji, H.; Katoh, S., Angiotensin-I converting 515 enzyme (ACE) inhibitory mechanism of tripeptides containing aromatic residues. J Biosci Bioeng 516 2008, $106(3), 310-2$.

517 36. Huang, G. J.; Lu, T. L.; Chiu, C. S.; Chen, H. J.; Wu, C. H.; Lin, Y. C.; Hsieh, W. T.; Liao, J. 518 C.; Sheu, M. J.; Lin, Y. H., Sweet potato storage root defensin and its tryptic hydrolysates exhibited 519 angiotensin converting enzyme inhibitory activity in vitro. Bot Stud 2011, 52 (3), 257-264.

520 37. O'Keeffe, M. B.; Norris, R.; Alashi, M. A.; Aluko, R. E.; FitzGerald, R. J., Peptide 521 identification in a porcine gelatin prolyl endoproteinase hydrolysate with angiotensin converting 522 enzyme (ACE) inhibitory and hypotensive activity. J Funct Foods 2017, 34, 77-88.

523 38. Bailey, C. J.; Tahrani, A. A.; Barnett, A. H., Future glucose-lowering drugs for type 2 524 diabetes. Lancet Diabetes Endocrinol 2016.

525 39. Boots, J.-W. P. Protein hydrolysate enriched in peptides inhibiting DPP-IV and their use. 526 WO2006068480A2, 2006.

527 40. Lammi, C.; Zanoni, C.; Arnoldi, A.; Vistoli, G., Peptides derived from soy and lupin protein 528 as Dipeptidyl-Peptidase IV inhibitors: In vitro biochemical screening and in silico molecular 529 modeling study. J Agric Food Chem 2016, 64 (51), 9601-9606.

530 41. Nongonierma, A. B.; FitzGerald, R. J., Investigation of the Potential of Hemp, Pea, Rice and 531 Soy Protein Hydrolysates as a Source of Dipeptidyl Peptidase IV (DPP-IV) Inhibitory Peptides. Food 532 Dig Res Curr Opin 2015, 6 (1-3), 19-29.

533 42. Amigo-Benavent, M.; Clemente, A.; Caira, S.; Stiuso, P.; Ferranti, P.; del Castillo, M. D., Use 534 of phytochemomics to evaluate the bioavailability and bioactivity of antioxidant peptides of soybean $535 \quad \beta$-conglycinin. Electrophoresis 2014, 35 (11), 1582-9. 
536 43. Regazzo, D.; Mollé, D.; Gabai, G.; Tomé, D.; Dupont, D.; Leonil, J.; Boutrou, R., The (193-

537 209) 17-residues peptide of bovine $\beta$-casein is transported through Caco-2 monolayer. Mol Nutr Food

538 Res 2010, 54 (10), 1428-35.

539 44. Miguel, M.; Dávalos, A.; Manso, M. A.; de la Peña, G.; Lasunción, M. A.; López-Fandiño,

540 R., Transepithelial transport across Caco-2 cell monolayers of antihypertensive egg-derived peptides.

541 PepT1-mediated flux of Tyr-Pro-Ile. Mol Nutr Food Res 2008, 52 (12), 1507-13.

542

543

544

545

546

547

548

549

550

551

552

553

554

555

556

557

558

559

560

561

562

563

564

565

566

567

\section{Captions of Figures}

Figure 1. Tricine-SDS-PAGE of hempseed protein hydrolysates. M (marker) 26.6-3.5 kDa. Pep, Tryp, Panc, Cod represent the four hydrolysates.

Figure 2. A) Percent distribution of identified peptides according to their parent proteins. B) Venn diagrams of the total number of identified proteins in each hydrolysate.

Figure 3. A) MW distribution (in Da) of the identified peptides in each hydrolysate. B) Hierarchical clustering analysis (HCA) with dendrogram of amino acid data set composition of each hydrolysate.

Figure 4. Effect of the hydrolysates on the catalytic domain of HMGCoAR. Bars indicate the effects of each hydrolysate on the HMGCoAR activity at the following concentrations: (A) peptic hydrolysate $(0.1,0.25,0.35,0.5$, and $1.0 \mathrm{mg} / \mathrm{mL})$; (B) tryptic hydrolysate $(0.2,0.5$, and $1 \mathrm{mg} / \mathrm{mL})$; (C) pancreatic hydrolysate $(1.0,2.0 \mathrm{mg} / \mathrm{mL})$; (D) co-digested hydrolysate $(0.2,0.5$, and $1.0 \mathrm{mg} / \mathrm{mL}$ ). HMGCoAR, physiologically, catalyzes the four-electron reduction of HMGCoA to coenzyme A $(\mathrm{CoA})$ and mevalonate $(\mathrm{HMG}-\mathrm{CoA}+2 \mathrm{NADPH}+2 \mathrm{H}+>$ mevalonate + $2 \mathrm{NADP}++\mathrm{CoA}-\mathrm{SH})$. In this assay, the decrease in absorbance at $340 \mathrm{~nm}$, which represents the oxidation of NADPH by the catalytic subunit of HMGCoAR in the presence of the substrate HMG-CoA, was measured spectrophotometrically. Data points represent averages \pm SD of three independent experiments in triplicate. $(*) p<0.05,(* *) p<0.001$, and $(* * *) p<0.0001$ versus control (C). 
568 Figure 5. PeptideRanker score of potentially bioactive peptides vs. Total Protein Spectrum 569 Intensity (TPSI) of parent proteins.

570 
Table 1. Predicted bioactive peptides by PeptideRanker and BIOPEP.

\begin{tabular}{|c|c|c|c|c|c|c|}
\hline Protein Acc. N. & Peptide sequence & TPSI $x 1^{6}$ & Enzyme & Score $^{a}$ & Potential bioactive peptides $^{b}$ & Biological functions $^{b}$ \\
\hline \multirow[t]{4}{*}{ A0A0C5ARZ4 } & SHLNWVCIFLGFHSFGLYI & 67,6 & Pep & 0.94 & GLY & Regulating phospho inositol mechanism peptide \\
\hline & & & & & GF, IF, GL, HL, FG, LG, SF, LN, GLY, IFL & ACE-inhibitor \\
\hline & & & & & HL, LY & Antioxidative \\
\hline & & & & & $\begin{array}{l}\text { FL, WV, HL, GL, GF, HS, LN, NW, SF, SH, } \\
\text { YI }\end{array}$ & Dipeptidyl peptidase IV inhibitor \\
\hline \multirow[t]{2}{*}{ A0A0C5ARQ8 } & QIQFEGFCRF & 29,9 & Pep & 0.92 & RF. GF, EG & ACE-inhibitor \\
\hline & & & & & EG, GF, IQ, QF, QI & Dipeptidyl peptidase IV inhibitor \\
\hline \multirow[t]{2}{*}{ A0A0C5ARZ4 } & IPDKANLGFRFP & 67,6 & Pep & 0.87 & RF, FP, IP, GF, FR, LG, KA & ACE-inhibitor \\
\hline & & & & & KA, IP, FP, FR, GF, NL & Dipeptidyl peptidase IV inhibitor \\
\hline \multirow[t]{4}{*}{ A0A0C5B2L0 } & SSEKGMIATFCCITGLL & 38,4 & Cod & 0.86 & IA, GM, GL, KG, TG, EK, TF & ACE inhibitor \\
\hline & & & & & LL & Glucose uptake stimulating peptide \\
\hline & & & & & SE & Stimulating vasoactive substance release \\
\hline & & & & & IA, EK, GL, AT, KG, MI, TF, TG & Dipeptidyl peptidase IV inhibitor \\
\hline \multirow[t]{5}{*}{ H9A8L3 } & IPWTQLSPIRCAAESWAHM & 44,1 & Pep & 0.80 & IR, LSP, IP, AA, TQ, AH, WA & ACE inhibitor \\
\hline & & & & & AH, PWT, PW, IR & Antioxidative \\
\hline & & & & & IR & Renin inhibitor \\
\hline & & & & & WA & Activating ubiquitin-mediated proteolysis \\
\hline & & & & & $\begin{array}{l}\text { IP, SP, WA, AA, WT, AE, AH, ES, IR, PI, } \\
\text { PW, QL, SW, TQ }\end{array}$ & Dipeptidyl peptidase IV inhibitor \\
\hline \multirow[t]{3}{*}{ C6KI62 } & PIGISDWNSLFWIVHP & 41,9 & Cod & 0.79 & LF, IG, GI, HP & ACE inhibitor \\
\hline & & & & & IV & Glucose uptake stimulating peptide \\
\hline & & & & & HP, SL, WI, WN, GI, PI, VH & Dipeptidyl peptidase IV inhibitor \\
\hline \multirow[t]{3}{*}{ A0A0C5APZ1 } & $\begin{array}{l}\text { LPDTHGEAHYSTCMLLAGILLK } \\
\text { MG }\end{array}$ & 40,2 & Pep & 0.78 & $\begin{array}{l}\text { HY, LA, GI, AG, MG, HG, GE, EA, AH, IL, } \\
\text { ST }\end{array}$ & ACE inhibitor \\
\hline & & & & & II, IL & Glucose uptake stimulating peptide \\
\hline & & & & & $\mathrm{AH}, \mathrm{LK}$ & Antioxidative \\
\hline
\end{tabular}




\begin{tabular}{|c|c|c|c|c|c|c|}
\hline & & & & & LA & Activating ubiquitin-mediated proteolysis \\
\hline & & & & & $\begin{array}{l}\text { LA, LP, LL, AG, AH, GE, GI, HY, IL, MG, } \\
\text { ML, TH, YS }\end{array}$ & Dipeptidyl peptidase IV inhibitor \\
\hline \multirow[t]{6}{*}{ A0A088MFF4 } & PGRVLSLFVTLTLGWPLY & 69,9 & Pep & 0.74 & PG & Prolyl endopeptidase inhibitor \\
\hline & & & & & LY, LF, PL, GW, GR, LG, PG & ACE inhibitor \\
\hline & & & & & $\mathrm{VL}$ & Glucose uptake stimulating peptide \\
\hline & & & & & PG & $\begin{array}{l}\text { Peptide regulating the stomach mucosal membrane } \\
\text { activity }\end{array}$ \\
\hline & & & & & LY, WPL & Antioxidative \\
\hline & & & & & WP, SL, PL, GW, LT, PG, TL, VL, VT & Dipeptidyl peptidase IV inhibitor \\
\hline \multirow[t]{2}{*}{ А0А090СХР8 } & DIFNPRGG & 359,0 & Cod & 0.74 & PR, IF, GG & ACE inhibitor \\
\hline & & & & & $\mathrm{NP}, \mathrm{FN}, \mathrm{GG}, \mathrm{RG}$ & Dipeptidyl peptidase IV inhibitor \\
\hline \multirow[t]{4}{*}{ A6P6W0 } & RIWGEKYFGKNFNRLVKVK & 63,0 & Pep & 0.73 & $\begin{array}{l}\text { RL, FGK, IW, VK, FG, GK, WG, GE, NF, } \\
\text { KY, EK }\end{array}$ & ACE inhibitor \\
\hline & & & & & LV & Glucose uptake stimulating peptide \\
\hline & & & & & VKV, WG & Antioxidative \\
\hline & & & & & $\begin{array}{l}\text { EK, WG, FN, GE, IW, KV, KY, LV, NF, NR, } \\
\text { RI, RL, RL, VK, YF }\end{array}$ & Dipeptidyl peptidase IV inhibitor \\
\hline \multirow[t]{2}{*}{ A7IZZ1 } & VRFEPQFSYFRI & 40,9 & Pep & 0.71 & RF, FR, VR, SY, PQ, FEP & ACE inhibitor \\
\hline & & & & & EP, VR, FR, PQ, QF, RI, SY, YF & Dipeptidyl peptidase IV inhibitor \\
\hline \multirow[t]{2}{*}{ E5DL82 } & PRNSWISCNMRLNAITL & 64,8 & Cod & 0.70 & RL, PR, LN, AI & ACE inhibitor \\
\hline & & & & & WI, LN, MR, NA, NM, RL, RN, SW, TL & Dipeptidyl peptidase IV inhibitor \\
\hline \multirow[t]{5}{*}{ H9A1V5 } & NDVKKFIAGQVASFKRL & 30,8 & Cod & 0.69 & RL, VK, IA, KR, AG, GQ, SF, KF, FKR & ACE inhibitor \\
\hline & & & & & GQ & Neuropeptide \\
\hline & & & & & KK & Bacterial permease ligand \\
\hline & & & & & $\mathrm{KF}$ & Renin inhibitor \\
\hline & & & & & $\begin{array}{l}\text { VA, GQ, IA, AG, AS, KF, KK, KR, ND, QV, } \\
\text { RL, SF, VK }\end{array}$ & Dipeptidyl peptidase IV inhibitor \\
\hline \multirow[t]{2}{*}{ H9A8L2 } & SPIGGGPEQLVMFVVLKNGY & 39,9 & Cod & 0.68 & GP & Prolyl endopeptidase inhibitor \\
\hline & & & & & MF, GY, GP, IG, GG, NG & ACE inhibitor \\
\hline
\end{tabular}




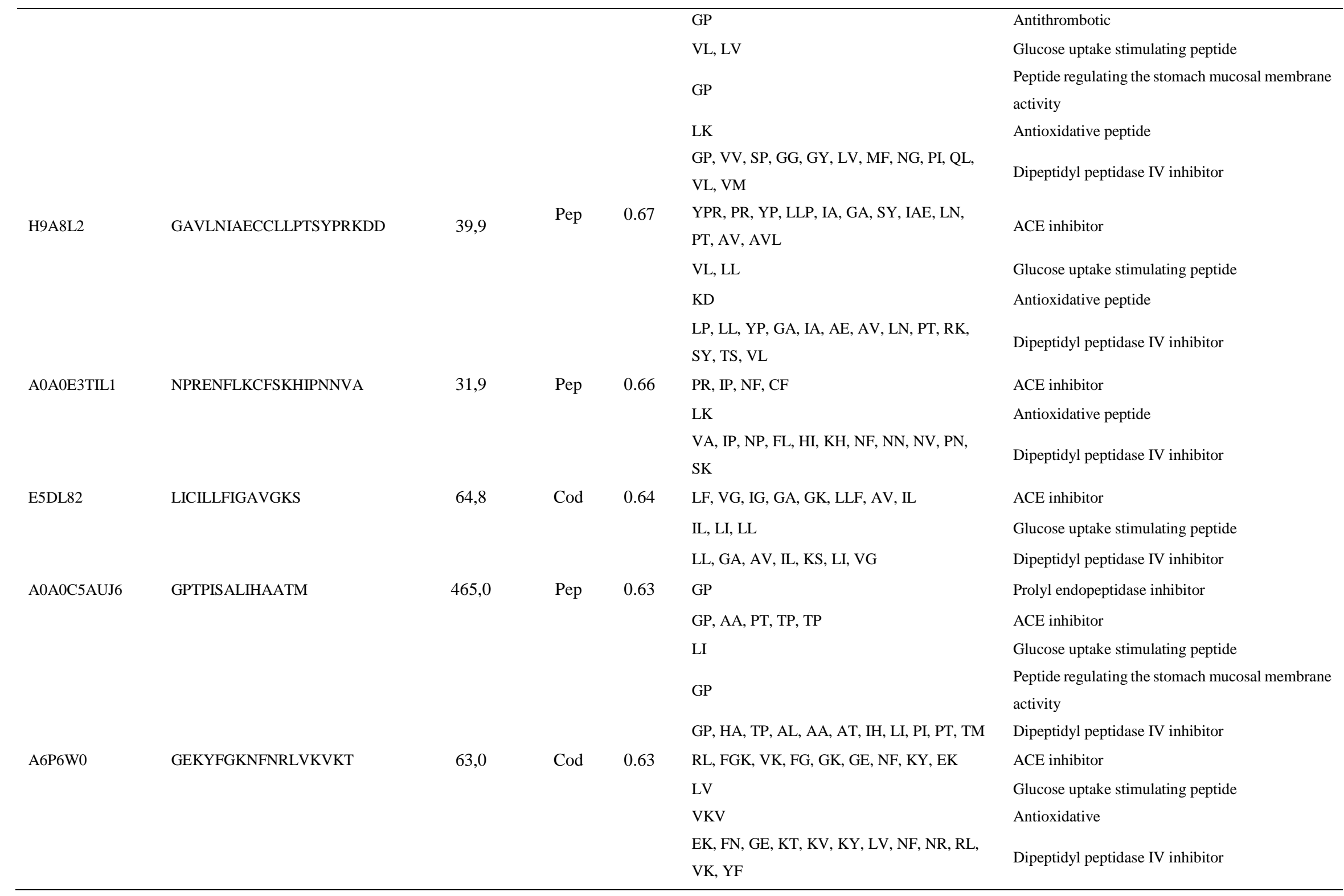




\begin{tabular}{|c|c|c|c|c|c|c|}
\hline \multirow[t]{5}{*}{ A0A0C5B2I8 } & ATGRIVCANCHLANKPVDIEVP & 19,4 & Cod & 0.61 & LA, VP, HL, GR, TG, NK, KP, IE, EV & ACE inhibitor \\
\hline & & & & & IV & Glucose uptake stimulating peptide \\
\hline & & & & & HL, KP & Antioxidative \\
\hline & & & & & LA & Ubiquitin-mediated proteolysis activating peptide \\
\hline & & & & & LA, VP, KP, HL, AT, EV, PV, RI, TG, VD & Dipeptidyl peptidase IV inhibitor \\
\hline \multirow[t]{3}{*}{ H9A1V5 } & ALSKNSMVKKFNLSSIKYIG & 30,8 & Pep & 0.61 & VK, IG, KY, KF, IKY & ACE inhibitor \\
\hline & & & & & $\mathrm{KF}$ & Renin inhibitor \\
\hline & & & & & $\begin{array}{l}\text { AL, FN, KF, KK, KY, MV, NL, SI, SK, VK, } \\
\text { YI }\end{array}$ & Dipeptidyl peptidase IV inhibitor \\
\hline \multirow[t]{6}{*}{ E5DKP2 } & YSIQKVFSAGRLVGGEKGPYSV & 60,7 & Tryp & 0.60 & GP & Prolyl endopeptidase inhibitor \\
\hline & & & & & $\begin{array}{l}\text { RL, VF, GP, VG, AG, GR, KG, GE, GG, QK, } \\
\text { EK, KGP, EKGP }\end{array}$ & ACE inhibitor \\
\hline & & & & & LV & Glucose uptake stimulating peptide \\
\hline & & & & & GP & $\begin{array}{l}\text { Peptide regulating the stomach mucosal membrane } \\
\text { activity }\end{array}$ \\
\hline & & & & & GGE & Antioxidative \\
\hline & & & & & $\begin{array}{l}\text { GP, EK, AG, GE, GG, IQ, KG, KV, LV, PY, } \\
\text { RL, SI, SV, VF, VG, YS }\end{array}$ & Dipeptidyl peptidase IV inhibitor \\
\hline
\end{tabular}

\section{a. From PeptideRanker}

\section{b. From BIOPEP}




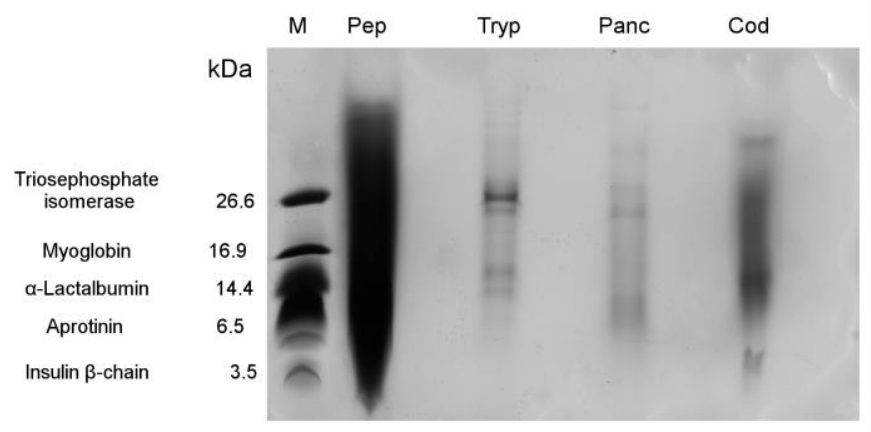

Figure 1 
A)
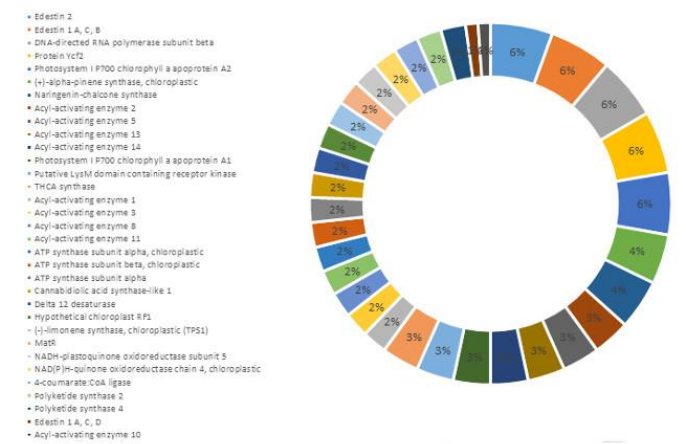

- Phenylalanine ammonia-lyase

- Ribulose 1,5-bisphosphate

carboxylase/oxygenase large subunit

- ATP synthase subunit beta

\# Chalcone synthase-like protein 1

- Ribosomal protein S3

- Acyl-activating enzyme 6

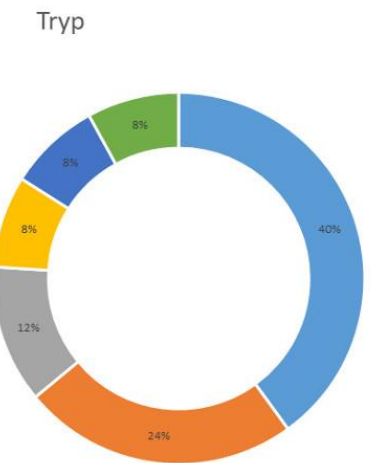

chloroplastic

Panc

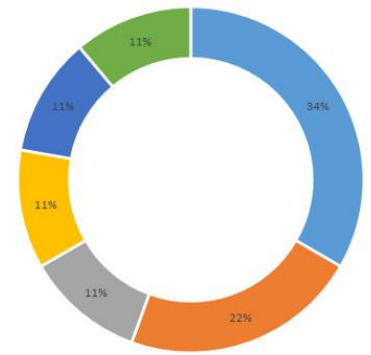

Cod
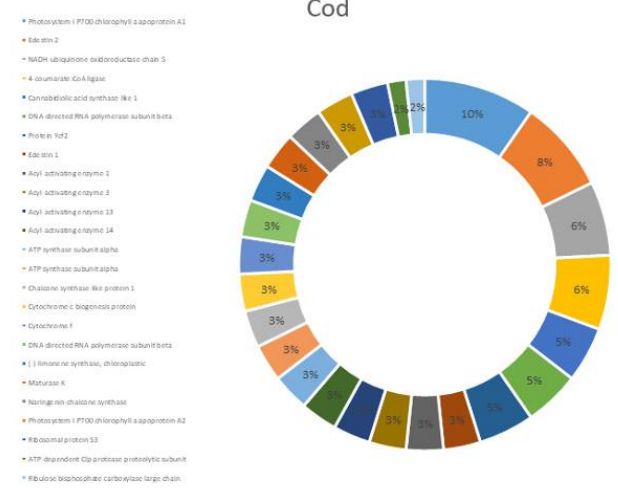

B)

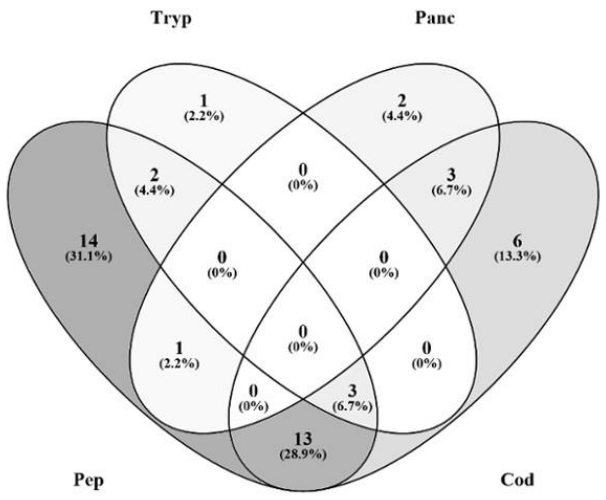

Figure 2 
A)

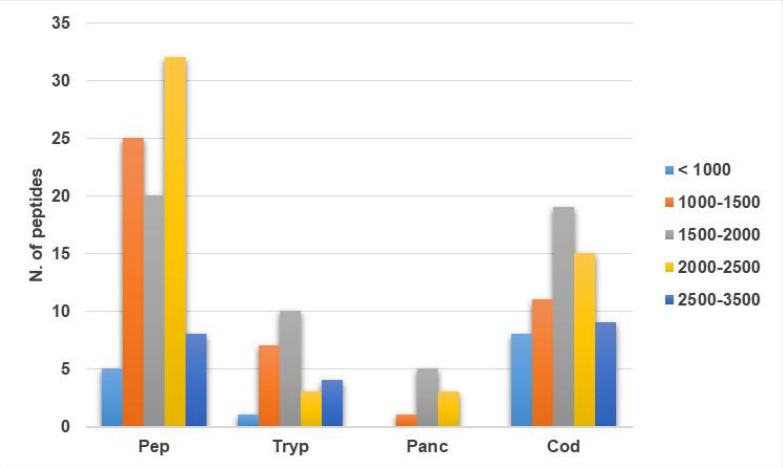

B)

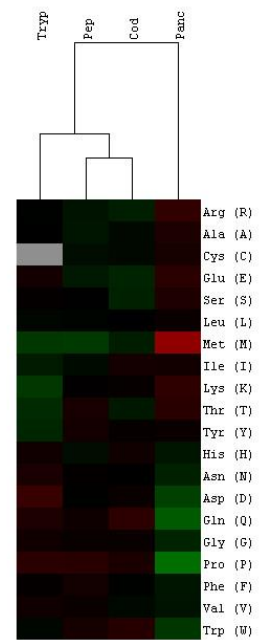

Figure 3 

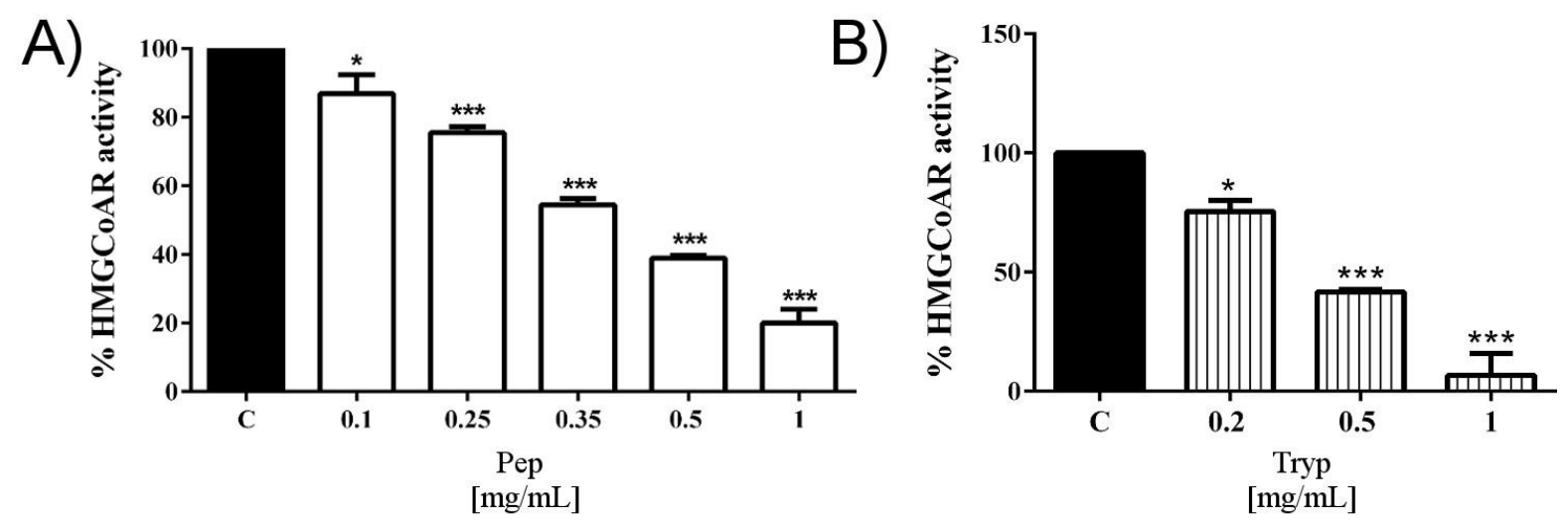

C)

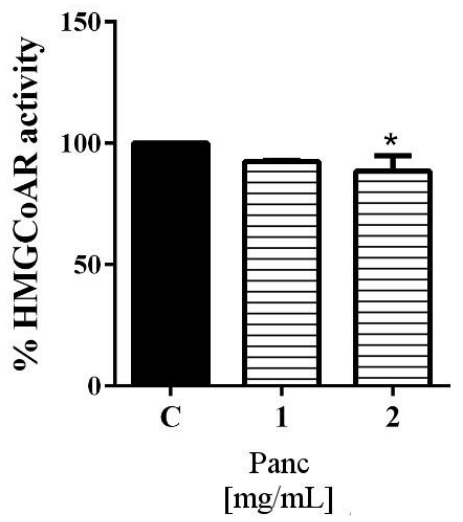

D)

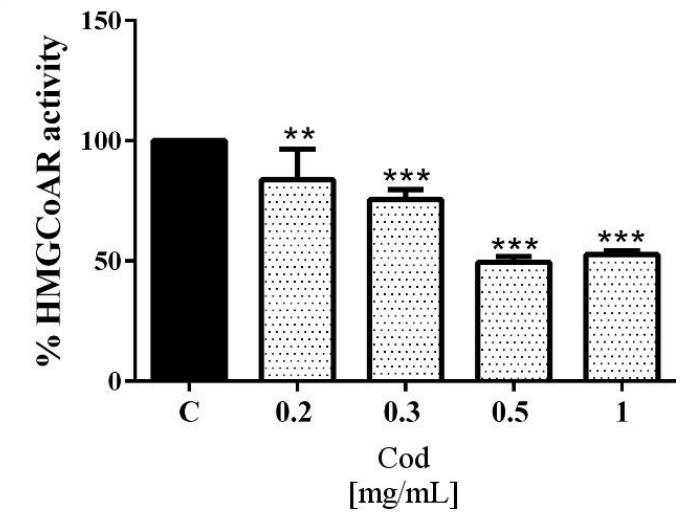

Figure 4 


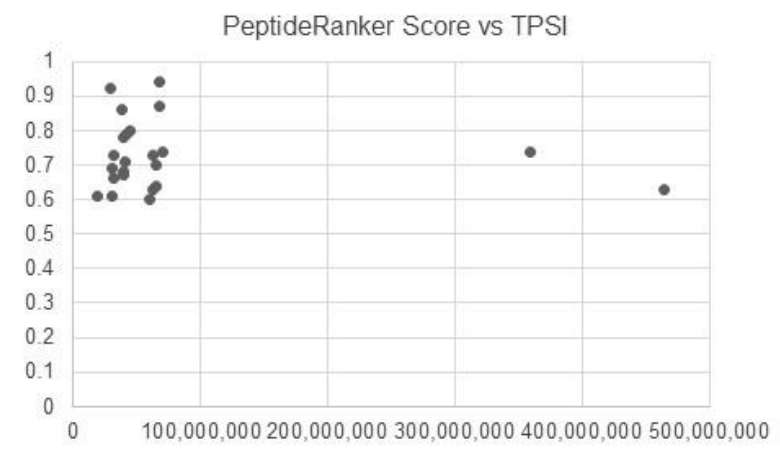

Figure 5. 


\section{Hempseed peptide exploration}

$$
0^{\circ}
$$

3

IIn

1

HMGCOAR inhibition and

screening of potentially

bioactive peptides

1

Pepsin

Trypsin

Pancreatin
Codigested

Enzymatic and simulated

Gl hempseed protein

hydrolysis

TOC

2

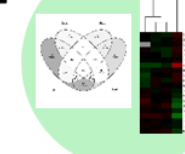

Chemical composition of

hydrolysates by MS/MS 